\title{
Drosophila melanogaster as a model for basal body research
}

\author{
Swadhin Chandra Jana ${ }^{1 *}$, Mónica Bettencourt-Dias ${ }^{1 *}$, Bénédicte Durand ${ }^{2 *}$ and Timothy L. Megraw ${ }^{3^{*}}$
}

\begin{abstract}
The fruit fly, Drosophila melanogaster, is one of the most extensively studied organisms in biological research and has centrioles/basal bodies and cilia that can be modelled to investigate their functions in animals generally. Centrioles are nine-fold symmetrical microtubule-based cylindrical structures required to form centrosomes and also to nucleate the formation of cilia and flagella. When they function to template cilia, centrioles transition into basal bodies. The fruit fly has various types of basal bodies and cilia, which are needed for sensory neuron and sperm function. Genetics, cell biology and behaviour studies in the fruit fly have unveiled new basal body components and revealed different modes of assembly and functions of basal bodies that are conserved in many other organisms, including human, green algae and plasmodium. Here we describe the various basal bodies of Drosophila, what is known about their composition, structure and function.
\end{abstract}

Keywords: Insects, Drosophila, Sensory function, Centriole, Male fertility, Motile and immotile cilia, Diverse basal bodies, Evolutionary cell biology

\section{The fly and its phylogeny}

The fruit fly Drosophila melanogaster is a widely used model organism for biological research in the disciplines of genetics, molecular biology, developmental biology, cell biology and behaviour. Thomas Hunt Morgan initiated the use of $D$. melanogaster with his first studies on heredity at Columbia University published in 1910. The fruit fly offers several advantages for biological studies, including short-generation time $\left(10\right.$ days at $\left.25^{\circ} \mathrm{C}\right)$, high fecundity, overall low maintenance costs and relative ease to perform genetics and cell biology experiments. Moreover, about $75 \%$ of known human disease genes have a recognizable match in the fruit fly genome; as such, Drosophila is used to understand the molecular mechanisms of diverse human diseases and conditions including cancer, ageing, infertility, neurodegenerative disorders and

\footnotetext{
*Correspondence: swadhin1cal@gmail.com; mdias@igc.gulbenkian.pt; benedicte.durand@univ-lyon1.fr; timothy.megraw@med.fsu.edu

1 Instituto Gulbenkian de Ciência, Rua da Quinta Grande, número 6, 2780-156 Oeiras, Portugal

${ }^{2}$ Institut NeuroMyogène, CNRS UMR-5310 INSERM-U1217, Université Claude Bernard Lyon-1, Lyon, Villeurbanne, France

${ }^{3}$ Department of Biomedical Sciences, Florida State University, Tallahassee, FL 32306, USA

Full list of author information is available at the end of the article
}

drug abuse [1]. Finally, the genomes of D. melanogaster and eleven other Drosophila species have been sequenced and annotated, as well as the genomes of other insects important in human disease, agriculture and manufacturing (e.g. mosquito, silkworm and honeybee) (Fig. 1a). These tools allow biological processes to be studied and compared in evolutionarily related (e.g. Drosophila Sp.) [2], close (e.g. mosquito and honeybee) [3] and distant species (e.g. human and plasmodium) $[4,5]$.

The fruit fly is also a preferred model organism to study centrosome and cilia biology. First, most Drosophila proteins required for centrosome and cilia biogenesis are conserved among eukaryotes and are involved in human centrosome and ciliary diseases, such as microcephalies and ciliopathies [5-10]. Second, fruit fly mutants of centrosome and ciliary proteins are not embryonic lethal and can thus be more easily studied for sensory neuron and sperm functions [11,12]. Third, Drosophila harbours diverse basal bodies and cilia that are assembled in different modes that are conserved in many other organisms (Fig. 1b; [5]). Finally, many tools are available to study basal bodies and cilia, such as mutants, RNAi lines, transgenic lines with tagged proteins and antibody reagents [5]. 


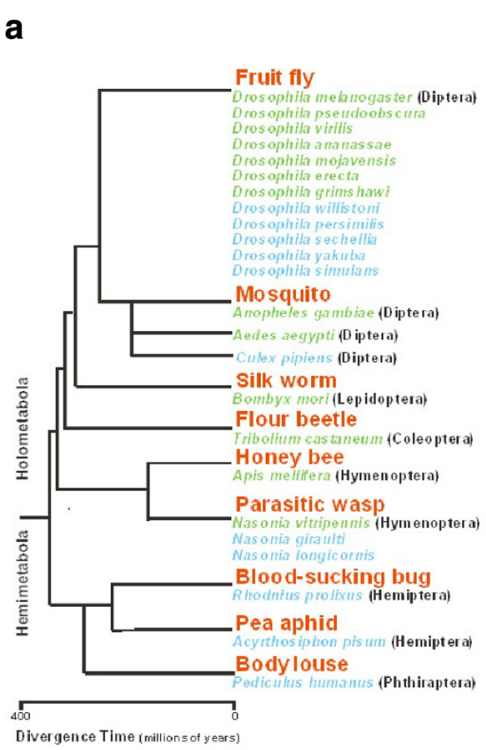

b
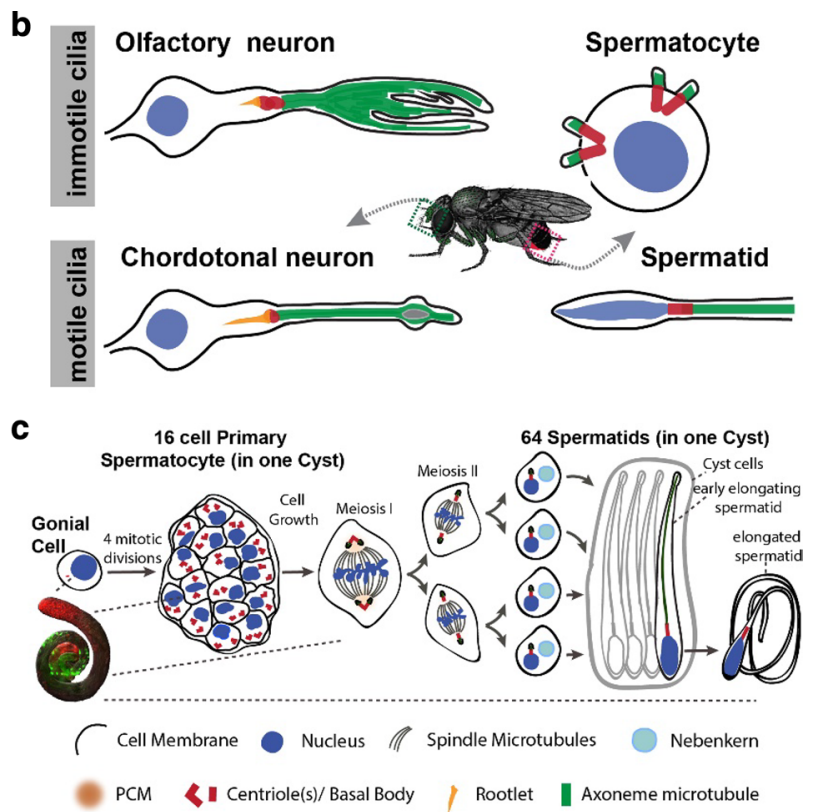

Fig. 1 The fruit fly as a cell and evolutionary biology model organism to study basal bodies. a Phylogenetic relationships of the insects whose genomes have been sequenced. Green indicates genomes that have been fully sequenced (more than $8 \times$ coverage), blue indicates genomes, where the sequencing has not been completed (less than $8 \times$ coverage). The sequenced genomes cover about 350 million years of insect evolution. From: http://www2.bio.ku.dk/insect_genomics/project/. b Diagrams, not to scale, of a variety of ciliated cells that grow morphologically different cilia in the adult fly. c Schematic representation of Drosophila spermatogenesis. A germline stem cell after division gives rise to a gonial cell that in turn undergoes four rounds of incomplete mitotic divisions to produce a 16-cell cyst of interconnected primary spermatocytes. Primary spermatocytes go through a long G2 phase when centrioles/basal bodies elongate and migrate to the cell membrane where each centriole grows a cilium. Each spermatocyte then undergoes two consecutive meiotic divisions without either DNA replication or basal body duplication. As a result, each early spermatid harbours one basal body that templates the sperm flagellum axoneme

\section{Diverse cilia in Drosophila}

While most cells in the fruit fly have no cilia, its type-I sensory neurons and sperm cells have cilia with a variety of configurations and defects in cilia affect diverse sensory functions, such as touch, coordination, taste, olfaction and hearing, and cause sterility [12-14], offering diverse opportunities for cilia and basal body research. Ciliary functions can be tested in Drosophila by measuring the response to sensory stimuli, behaviour and/or fertility [12-14].

Sensory reception is mediated by a single cilium on each type-I sensory neuron of the peripheral nervous system (Fig. 1b). Type-I sensory neuron cilia can generally be divided into two categories: (1) cilia in external sensory neurons $(9+0$ type axonemes without dynein arms) are considered immotile [14] and (2) cilia in chordotonal neurons $(9+0$ type axonemes with dynein arms) are believed to be motile [15]. Notably, all cilia on sensory neurons require intraflagellar transport (IFT) for their assembly $[16,17]$ and the function of olfactory cilia in external sensory neurons require hedgehog signalling, a pathway that is conserved in mammalian cilia [18].
Drosophila testes harbour sperm cells and their precursors that also grow cilia (Fig. 1b). While sperm cilia are motile $(9+2)$, sperm precursor cells (spermatocytes) have immotile cilia $(9+0 / 1)$ [19-22]. Each spermatocyte has four long centrioles, which convert into basal bodies and therefore assemble four cilia. Following two rounds of meiotic division, spermatids inherit a single basal body that assembles the flagellum (Fig. 1c). The cilia in sperm and sperm precursor cells assemble in an IFT-independent manner [16, 17].

\section{Centriole identity and structure}

Most cycling cells have one centrosome with two centrioles at the beginning of the cell cycle, and two centrosomes, each with two centrioles, after their duplication in the later phases of the cycle (reviewed in [8]). Centrioles within centrosomes and/or basal bodies vary in their length and the organization of the outer microtubules (MT). For example, centrioles/basal bodies in the embryo and sensory neurons are short and made of nine doublet MTs (Fig. 2a i-ii, b-i [14, 23, 24]), whereas those in sperm cells are uniquely long and consist of nine triplet MTs (Fig. 2a iii-iv, b-ii [20, 21]). Thus, flies have 


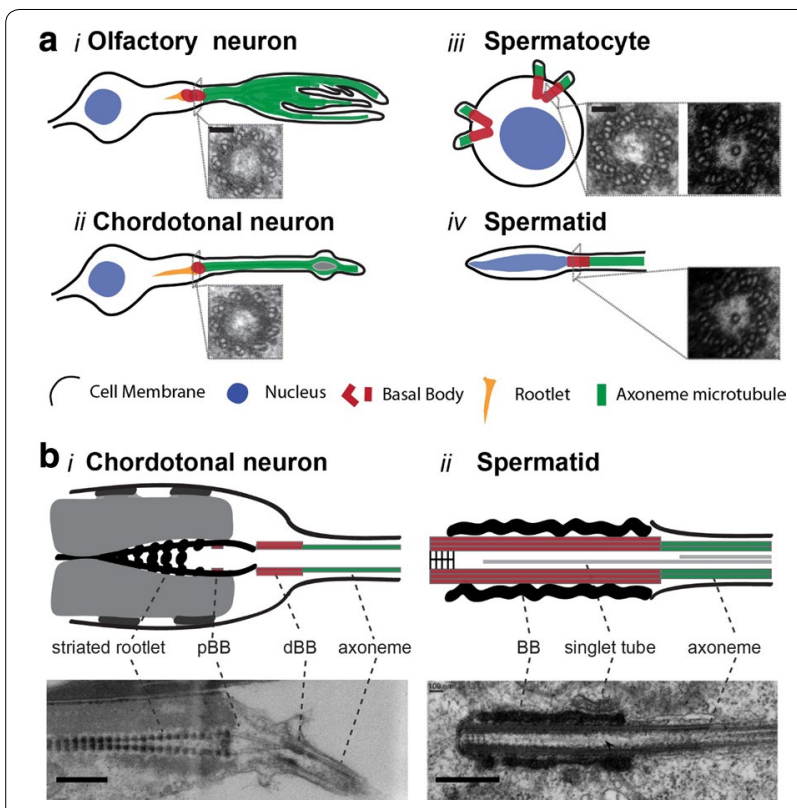

Fig. 2 The variety of basal bodies found in Drosophila. a Representative electron micrographs of the cross section view of the basal body in olfactory neurons (i), chordotonal neurons (ii), spermatocyte (iii) and spermatid (iv). b Schematics and representative electron micrographs of the longitudinal view of the basal body in chordotonal neurons ( $i$ ) and spermatid (ii). BB, pBB and $\mathrm{dBB}$ represent basal body, proximal basal body and distal basal body, respectively. Scale bars in $\mathbf{a}$ and $\mathbf{b}$ represent 100 and $500 \mathrm{~nm}$, respectively. The electron micrographs in a are reproduced with permission from $[20,23,54]$ and in b-ii from [20]

a diverse makeup to their centriolar microtubules, with some having doublet MTs, while others have triplet MTs similar to many protists and metazoa, such as plasmodium and mammals $[4,5]$.

Several EM studies elucidated the structures of Drosophila centrioles in cell culture [25], embryos [26], sensory neurons [23] and testis [22, 27]. Drosophila centrioles do not have distinct distal or subdistal appendages as their mammalian counterparts, and mother and daughter centrioles are indistinguishable at the EM level except for by their relative juxtaposition (the daughter attached to the mother at the proximal base) [28]. Curiously, despite lacking the distal and subdistal appendages on mother centrioles, Drosophila do have orthologs of key protein components of these structures such as Cep164 (CG9170) [10] and ninein (Bsg25D) [29]. Moreover, proteins have been identified that are specific for daughter centrioles like centrobin [30], and transgenes expressing the PACT domain from pericentrin-like protein (Plp) are enriched at the mother centriole [23, 31, 32 ]. In ciliated chordotonal neurons, these markers indicate that the cilium grows from the mother centriole. Thus, however, the lack of overt distal structures that adorn mother centrioles and are required in other organisms for ciliogenesis, mother centrioles are nevertheless distinguished by their ability to form cilia in Drosophila. Functionally, centrobin appears to confer daughter identity, as it restricts the daughter centriole from engaging in cilium assembly [23].

\section{Basal body origins and structure Centriole to basal body conversion}

Drosophila basal bodies, which display many unique features that are conserved in many other organisms, are converted from canonically formed centrioles in all ciliated tissues. In sensory neurons, no direct observation of the conversion of centrioles to basal bodies has been published. However, serial sections of neuronal cells by EM show centriolar structures only at the base of the cilia [33] and centriolar proteins only label the ciliary base of sensory neurons by microscopic imaging [23, 34-37]. Based on data from other arthropod chordotonal cilia, we can expect thin fibrous structures linking the MTs at the distal centriole to the membrane connections in the neurons [38], but complete description of how basal bodies anchor to membranes in Drosophila ciliated neurons is pending.

The centriole to basal body conversion was documented in sperm cells by exhaustive electron microscopy observations ([22] and recently [20,21]) and can be followed by live imaging of centriole behaviour during differentiation of sperm cells [39]. The basal bodies in the Drosophila testis grow exceptionally long during spermatocyte maturation (Fig. 1c) [22, 27, 40]. These giant centrioles/basal bodies are about $1.3 \mu \mathrm{m}$ long, including the short cilium-like region at their distal end, which is approximately $400 \mathrm{~nm}$ long and is the precursor for formation of the long sperm flagellum [41]. The basal bodies and short cilia in spermatocytes are unusual in several respects: the cilia assemble in G2 phase, all four basal bodies anchor at the plasma membrane and assemble cilia, and the cilia persist through two meiotic cell divisions (Fig. 1c) [21, 22, 27]. Inside the lumen of the spermatocyte and spermatid basal body, there is a single central tubule that is variable in length, but can extend into the transition zone and coincide with the axonemal central pair (Fig. 2a, b) [19, 20, 42]. This single MT appears to be stabilized by Bld10, a MT-binding protein required for centriole elongation and stability in the fruit fly, and promotes the formation and/or stability of the central pair of MTs within the sperm axoneme [20]. Despite the lack of distal appendages, spermatocyte and spermatid basal bodies have thin fibrous structures that link the $C$ tubules at the distal centriole to the membrane.

In the early spermatid, the basal body migrates to the nucleus and anchors to the nuclear envelope. As spermiogenesis proceeds, a pericentriolar material (PCM)-like 
toroid structure called the "centriolar adjunct" forms, encircling the proximal base of the giant centriole [43]. The function of the centriolar adjunct is unclear, but it appears to nurture the assembly of a new centriole during spermatozoan formation. Within the centriolar adjunct a unique structure forms called the proximal centriole-like structure (PCL), which contains several centriole proteins including Ana1, Ana2, Bld10, Sas-4 and Sas- 6 [42, 44, 45]. Assembly of the PCL requires the centriole biogenesis proteins Sas-6 and Sak/PLK4, and has a unique requirement for Poc1 that is not required for centriole assembly generally in Drosophila [44]. The PCL appears during spermatid differentiation and appears to be an atypical procentriole, which forms within the centriolar adjunct and might be reduced later on [46]. When delivered to the embryo at fertilization along with the giant basal body, the remainder of the PCL matures into a centriole, duplicates and assembles a centrosome that contributes to the first mitosis of the embryo [45].

The spermatozoan axoneme grows to a length of approximately $1800 \mu \mathrm{m}$-this is very long compared to humans for example, where the sperm tail is about $50 \mu \mathrm{m}$ long. As the axoneme assembles in the spermatid, it appears exposed in the cytoplasm. However, the distal $\sim 2 \mu \mathrm{m}$ of the axoneme is encased in membrane that is contiguous with the plasma membrane but is anchored to the axoneme at a structure called the "ring centriole" $[40,47,48]$. This distal portion of the growing flagellum appears to be a cilium with a distinct compartment, with typical transition zone proteins like unc, Cby, Mks1 and Cep290 localized at the ring centriole at the cilium base, despite the absence of a basal body [34, 49-51]. Thus, there is no basal body structure at the base of the spermatid distal compartmentalized cilium. The axoneme extends through the cytoplasm to the basal body anchored at the nucleus, yet the ring centriole appears to form a membrane barrier, which, as the axoneme grows, behaves as a migrating ciliary gate [51]. In the mouse, spermatozoan development follows a similar path, where a structure called the annulus appears to be analogous to the ring centriole [51].

The sensory neurons in Drosophila harbour ciliary rootlets of variable lengths depending on the neuron type (Fig. 2b-i), but these structures are not found in the testis $[22,36]$. The ciliary rootlet, a cytoskeletal structure comprised of striated fibres, assembles at the basal body in many ciliated organisms and cell types including insects and human [38]. Rootletin is a major component of rootlets in Drosophila and is required for rootlet assembly, but not for cilium assembly, and rootlets are necessary for sensory neuron function [36, 52].

\section{Basal body life cycle and other functions Does the basal body also have the function of a centrosome?}

Sensory neurons are terminally differentiated cells with the centriole pair residing at the tip of a single dendrite where one assembles a cilium. The basal bodies do not appear to function as an active MT-organizing centre (MTOC). In spermatocytes, in G2 phase, all 4 duplicated centrioles convert to basal bodies, dock to the plasma membrane and each one grows a primary cilium-like structure [20-22, 53, 54]. These cilia-like structures are not disassembled during meiosis. Basal bodies, together with the cilia-like structures, are internalized and mature into centrosomes that organize the meiotic spindle. Hence, basal bodies are able to simultaneously organize cilia and spindle poles [22] during Drosophila male meiosis (Fig. 1c). In mouse neuronal stem cells, a somewhat similar process occurs: the primary cilium is incompletely resorbed and the basal body with residual cilium participates in the following asymmetric mitosis [55].

\section{Do Drosophila have basal bodies at all stages of their life cycle? If not when?}

Ciliated cells are present only as type-I sensory neurons, which develop during mid-embryogenesis, and in spermatogenic cells at the beginning of larval stages in Drosophila. Ciliated neurons in adults are built during metamorphosis from sensory precursors derived from larval imaginal discs. Basal bodies are required to build the sensory cilia [11] and are maintained during ageing of sensory cells $[36,52]$. In male germ cells, basal bodies are formed in spermatocytes and maintained during spermatid maturation. In mature sperm, basal bodies are still present as seen by EM [22] but several basal body/centriolar markers are reduced [42, 44, $56,57]$, illustrating the remodelling of the basal body that occurs in late spermiogenesis and also observed in several other animal species by a phenomenon called "centrosome reduction" (see $[58,59])$.

\section{Identification of basal body components}

There have been no proteomics performed on isolated Drosophila basal bodies, but there was a proteomics survey done on isolated mature sperm [60]. The spermatozoan typically undergoes centrosome reduction during spermatogenesis $[58,61]$. So while this study did not reveal any new basal body components, it did reveal centrosome and centriole proteins that were retained in the mature sperm (see Table 1) [60]. Since Drosophila sperm require functional flagella, and flies have somatic cilia only on sensory neurons where they are required for a variety of sensory functions, genetic screens that involved neurological motor activity or male fertility identified some cilium and basal body components. Table 1 
Table 1 Proteomic, RNAi and genomic screens that identified Drosophila centriole or centrosome proteins

\begin{tabular}{|c|c|c|c|}
\hline Type of screen & System & Proteins identified & References \\
\hline Genetic screen for mechanosensation defects & In vivo genetic screen & Unc, Asterless (MecD), Cep290 (MecH) & {$[13,62,63]$} \\
\hline Genetic screen for male infertility & In vivo genetic screen & Asterless, Spd-2 & {$[64,65]$} \\
\hline RNAi & Cell culture & Ana1, Ana2, Ana3 & {$[66]$} \\
\hline RNAi & Cell culture & Bld10, CP110, Cep97, Rcd4 & {$[67]$} \\
\hline Proteomic & Mature sperm & $\begin{array}{l}\text { Ana1, Ana3, Asp, Bld10, Grip163, Ninein, Plp, } \\
\text { Rootletin }\end{array}$ & {$[60]$} \\
\hline Proteomic & $\begin{array}{l}\text { Isolated blastoderm } \\
\text { embryo centrosomes }\end{array}$ & $\begin{array}{l}\text { CG11148, Cort, Crm, elF-4a, Feo, Lam, } \\
\text { Nup153, TFAM }\end{array}$ & {$[68]$} \\
\hline Proteomic & $\begin{array}{l}\text { Isolated blastoderm } \\
\text { embryo centrosomes }\end{array}$ & $\begin{array}{l}\text { Ote; new phosphorylation sites } \\
\text { mapped in known centrosome proteins }\end{array}$ & {$[69]$} \\
\hline
\end{tabular}

summarizes genetic, RNAi, and proteomic screens that identified centriole components.

\section{Summary of notable basal body findings}

To summarize, Drosophila harbour diverse centriole/ basal bodies with doublet and triplet MTs. A notable feature associated with basal bodies in Drosophila is a lack of distal or subdistal appendages. A unique feature at the sperm basal body is the PCL: a procentriole that appears in the differentiating spermatid within a PCM-like structure called the centriolar adjunct. Another notable feature in the Drosophila testis is the ring centriole. The ring centriole is a unique example of a transition zone-like structure that creates a cilium compartment without a canonical basal body. A fourth notable feature, residing in the centre of the long spermatocyte and spermatid basal body, is a clear central tubule, which is probably a dynamic MT. It extends from the hub of the cartwheel at the proximal end of the basal body to the distal end, where it transitions into the central pair of MTs in the axoneme. Finally, another notable feature associated with the neuronal basal body is the rootlet, a conserved cytoskeletal structure comprised striated fibres. Rootletin, a conserved component of root-like structures, is required for rootlet assembly and thereby supports sensory cilia functions.

\section{Strengths and future of basal body research in Drosophila} Unique advantages offered by D. melanogaster as a model for basal body research is the variety of basal bodies encountered in this organism that are also found in many eukaryotes, as well as limited requirements for cilia in this organism to sensory neurons and sperm cells. The absence of basal bodies or disruption of basal body proteins in Drosophila results in the loss of sensory functions (touch, hearing, olfaction and taste perceptions) and male fertility. Genetic screens are therefore possible to identify the components involved in the above functions. Drosophila is also a great model to study alternative modes of: cilia assembly (IFT-independent in sperm); transition zone function (ring centriole; appears conserved in vertebrates); and centriole biogenesis (the PCL). Drosophila is also an important model to study conventional modes of: cilia assembly (IFT-dependent in neurons); centriole biogenesis and elongation (the centrioles of different types of MTs and lengths in neurons and sperm cells); and ciliary rootlet biogenesis (the rootlet in neurons). Moreover, the recent sequencing of the genomes of several other Drosophila species and other insects permits the applications of comparative studies of basal body assembly and function.

\section{Abbreviations \\ MT: microtubules; MTOC: microtubule-organizing center; IFT: intraflagellar transport; PCM: pericentriolar material; PCL: procentriole-like structure; BB: basal body; pBB: proximal basal body; dBB: distal basal body.}

\section{Authors' contributions}

$\mathrm{SCJ}, \mathrm{MBD}, \mathrm{BD}$ and TLM equally wrote the manuscript and SCJ generated figures. All authors read and approved the final manuscript.

\section{Author details}

${ }^{1}$ Instituto Gulbenkian de Ciência, Rua da Quinta Grande, número 6, 2780-156 Oeiras, Portugal. ${ }^{2}$ Institut NeuroMyogène, CNRS UMR-5310 INSERM-U1217, Université Claude Bernard Lyon-1, Lyon, Villeurbanne, France. ${ }^{3}$ Department of Biomedical Sciences, Florida State University, Tallahassee, FL 32306, USA.

\section{Acknowledgements}

We apologize to colleagues whose work was not discussed or cited due to space constraints. SCJ is supported by the Fundação Portuguesa para a Ciência e Tecnologia Fellowship (SFRH/BPD/87479/2012). MBD laboratory is supported by an EMBO installation grant, an ERC Starting Grant (PFE-GIUEERC-2010-StG-261344) and Instituto Gulbenkian de Ciência, Portugal. BD laboratory is funded by Fondation pour la recherche Médicale (FRM DEQ 20131029168) Grant.

\section{Competing interests}

The authors declare that they have no competing interests.

Received: 14 January 2016 Accepted: 1 April 2016

Published online: 05 July 2016 


\section{References}

1. Brandt A, Vilcinskas A. The fruit fly Drosophila melanogaster as a model for aging research. Adv Biochem Eng Biotechnol. 2013;135:63-77.

2. Clark AG, Eisen MB, Smith DR, Bergman CM, Oliver B, Markow TA, Kaufman TC, Kellis M, Gelbart W, lyer VN, et al. Evolution of genes and genomes on the Drosophila phylogeny. Nature. 2007;450:203-18.

3. Consortium, T.H.G.S. Insights into social insects from the genome of the honeybee Apis mellifera. Nature. 2006;443:931-49.

4. Marques SR, Ramakrishnan C, Carzaniga R, Blagborough AM, Delves MJ, Talman AM, Sinden RE. An essential role of the basal body protein SAS-6 in Plasmodium male gamete development and malaria transmission. Cell Microbiol. 2015;17:191-206.

5. Vieillard J, Duteyrat JL, Cortier E, Durand B. Imaging cilia in Drosophila melanogaster. Methods Cell Biol. 2015;127:279-302

6. Avidor-Reiss T, Maer AM, Koundakjian E, Polyanovsky A, Keil T, Subramaniam S, Zuker CS. Decoding cilia function: defining specialized genes required for compartmentalized cilia biogenesis. Cell. 2004;117:527-39.

7. Carvalho-Santos Z, Machado P, Branco P, Tavares-Cadete F, RodriguesMartins A, Pereira-Leal JB, Bettencourt-Dias M. Stepwise evolution of the centriole-assembly pathway. J Cell Sci. 2010;123:1414-26.

8. Bettencourt-Dias M, Hildebrandt F, Pellman D, Woods G, Godinho SA. Centrosomes and cilia in human disease. Trends Genet. 2011:27:307-15.

9. Chavali PL, Putz M, Gergely F. Small organelle, big responsibility: the role of centrosomes in development and disease. Philos Trans R Soc Lond B Biol Sci. 2014;369:20130468

10. Hodges ME, Scheumann N, Wickstead B, Langdale JA, Gull K. Reconstructing the evolutionary history of the centriole from protein components. J Cell Sci. 2010;123:1407-13.

11. Basto R, Lau J, Vinogradova T, Gardiol A, Woods CG, Khodjakov A, Raff JW. Flies without centrioles. Cell. 2006;125:1375-86.

12. Dubruille R, Laurencon A, Vandaele C, Shishido E, Coulon-Bublex M, Swoboda P, Couble P, Kernan M, Durand B. Drosophila regulatory factor $X$ is necessary for ciliated sensory neuron differentiation. Development. 2002;129:5487-98.

13. Kernan M, Cowan D, Zuker C. Genetic dissection of mechanosensory transduction: mechanoreception-defective mutations of Drosophila. Neuron. 1994;12:1195-206.

14. Jana SC, Girotra M, Ray K. Heterotrimeric kinesin-II is necessary and sufficient to promote different stepwise assembly of morphologically distinct bipartite cilia in Drosophila antenna. Mol Biol Cell. 2011:22:769-81.

15. Kavlie RG, Kernan MJ, Eberl DF. Hearing in Drosophila requires TilB, a conserved protein associated with ciliary motility. Genetics. 2010;185:177-88.

16. Han YG, Kwok BH, Kernan MJ. Intraflagellar transport is required in Drosophila to differentiate sensory cilia but not sperm. Curr Biol. 2003;13:1679-86.

17. Sarpal R, Todi SV, Sivan-Loukianova E, Shirolikar S, Subramanian N, Raff EC, Erickson JW, Ray K, Eberl DF. Drosophila KAP interacts with the kinesin II motor subunit KLP64D to assemble chordotonal sensory cilia, but not sperm tails. Curr Biol. 2003;13:1687-96.

18. Kuzhandaivel A, Schultz SW, Alkhori L, Alenius M. Cilia-mediated hedgehog signaling in Drosophila. Cell Rep. 2014;7:672-80.

19. Roque H, Wainman A, Richens J, Kozyrska K, Franz A, Raff JW. Drosophila Cep135/Bld10 maintains proper centriole structure but is dispensable for cartwheel formation. J Cell Sci. 2012;125:5881-6.

20. Carvalho-Santos Z, Machado P, Alvarez-Martins I, Gouveia SM, Jana SC, Duarte P, Amado T, Branco P, Freitas MC, Silva ST, et al. BLD10/CEP135 is a microtubule-associated protein that controls the formation of the flagellum central microtubule pair. Dev Cell. 2012;23:412-24.

21. Riparbelli MG, Callaini G, Megraw TL. Assembly and persistence of primary cilia in dividing Drosophila spermatocytes. Dev Cell. 2012;23:425-32.

22. Tates AD. Cytodiferentiation during spermatogenesis in Drosophila melanogaster: an electron microscopy study. PhD thesis, Rijksunivrsiteit de Leiden, Netherlands; 1971

23. Gottardo M, Pollarolo G, Llamazares S, Reina J, Riparbelli MG, Callaini G, Gonzalez C. Loss of Centrobin Enables Daughter Centrioles to Form Sensory Cilia in Drosophila. Curr Biol. 2015;25:2319-24.

24. Gottardo M, Callaini G, Riparbelli MG. The Drosophila centriole - conversion of doublets into triplets within the stem cell niche. J Cell Sci. 2015;128:2437-42.

25. Echalier G, Ohanessian A. In vitro culture of Drosophila melanogaster embryonic cells. In vitro. 1970;6:162-72.
26. Callaini G, Whitfield WG, Riparbelli MG. Centriole and centrosome dynamics during the embryonic cell cycles that follow the formation of the cellular blastoderm in Drosophila. Exp Cell Res. 1997;234:183-90.

27. Fritz-Niggli H, Suda T. Formation and significance of centrioles: a study and new interpretation of the meiosis of Drosophila. Cytobiologie. 1972;5:12-41.

28. Gonzalez C, Tavosanis G, Mollinari C. Centrosomes and microtubule organisation during Drosophila development. J Cell Sci. 1998;111(Pt 18):2697-706.

29. Gopalakrishnan J, Mennella V, Blachon S, Zhai B, Smith AH, Megraw TL, Nicastro D, Gygi SP, Agard DA, Avidor-Reiss T. Sas-4 provides a scaffold for cytoplasmic complexes and tethers them in a centrosome. Nat Commun. 2011;2:359.

30. Januschke J, Llamazares S, Reina J, Gonzalez C. Drosophila neuroblasts retain the daughter centrosome. Nat Commun. 2011;2:243.

31. Conduit PT, Raff JW. Cnn dynamics drive centrosome size asymmetry to ensure daughter centriole retention in drosophila neuroblasts. Curr Biol. 2010:20:2187-92

32. Galletta BJ, Guillen RX, Fagerstrom CJ, Brownlee CW, Lerit DA, Megraw TL, Rogers GC, Rusan NM. Drosophila pericentrin requires interaction with calmodulin for its function at centrosomes and neuronal basal bodies but not at sperm basal bodies. Mol Biol Cell. 2014;25:2682-94.

33. Uga S, Kuwabara M. On the fine structure of the chordotonal sensillum in antenna of Drosophila melanogaster. J Electron Microsc. 1965;14:173-81.

34. Enjolras C, Thomas J, Chhin B, Cortier E, Duteyrat JL, Soulavie F, Kernan MJ, Laurencon A, Durand B. Drosophila chibby is required for basal body formation and ciliogenesis but not for Wg signaling. J Cell Biol. 2012;197:313-25

35. Ma L, Jarman AP. Dilatory is a Drosophila protein related to AZI1 (CEP131) that is located at the ciliary base and required for cilium formation. J Cell Sci. 2011;124:2622-30.

36. Chen JV, Kao LR, Jana SC, Sivan-Loukianova E, Mendonca S, Cabrera OA, Singh P, Cabernard C, Eberl DF, Bettencourt-Dias M, et al. Rootletin organizes the ciliary rootlet to achieve neuron sensory function in Drosophila. J Cell Biol. 2015;211:435-53.

37. Martinez-Campos M, Basto R, Baker J, Kernan M, Raff JW. The Drosophila pericentrin-like protein is essential for cilia/flagella function, but appears to be dispensable for mitosis. J Cell Biol. 2004;165:673-83.

38. Keil TA. Sensory cilia in arthropods. Arthropod Struct Dev. 2012;41:515-34

39. Rebollo E, Gonzalez C. Time-lapse imaging of male meiosis by phase-contrast and fluorescence microscopy. Methods Mol Biol. 2004;247:77-87.

40. Lindsley DL, Tokuyasu KT. Spermatogenesis. In: Ashburner M, Wright TRF, editors. The genetics and biology of Drosophila, vol. 2d. London: Academic Press; 1980. p. 225-94.

41. Tokuyasu KT. Dynamics of spermiogenesis in Drosophila melanogaster. VI. Significance of "onion" nebenkern formation. J Ultrastruct Res. 1975;53:93-112.

42. Mottier-Pavie V, Megraw TL. Drosophila bld10 is a centriolar protein that regulates centriole, basal body, and motile cilium assembly. Mol Biol Cell. 2009;20:2605-14.

43. Fuller MT. Spermatogenesis. In the development of Drosophila melanogaster, vol. 1. New York: Cold Spring Harbor Laboratory Press; 1993. p. 71-147.

44. Blachon S, Cai X, Roberts KA, Yang K, Polyanovsky A, Church A, Avidor-Reiss T. A proximal centriole-like structure is present in Drosophila spermatids and can serve as a model to study centriole duplication. Genetics. 2009:182:133-44.

45. Blachon S, Khire A, Avidor-Reiss T. The origin of the second centriole in the zygote of Drosophila melanogaster. Genetics. 2014;197:199-205.

46. Gottardo M, Callaini G, Riparbelli MG. Structural characterization of procentrioles in Drosophila spermatids. Cytoskeleton (Hoboken). 2015;72:576.

47. Phillips DM. Insect sperm: their structure and morphogenesis. J Cell Biol. 1970:44:243-77.

48. Johnson $\mathrm{HH}$. Peripheral migration of a centriole derivative in the spermatogenesis of oeligcanthus. Science. 1922:56:759-60.

49. Wei HC, Rollins J, Fabian L, Hayes M, Polevoy G, Bazinet C, Brill JA. Depletion of plasma membrane Ptdlns(4,5)P2 reveals essential roles for phosphoinositides in flagellar biogenesis. J Cell Sci. 2008;121:1076-84.

50. Fabian L, Brill JA. Drosophila spermiogenesis: big things come from little packages. Spermatogenesis. 2012;2:197-212. 
51. Basiri ML, Ha A, Chadha A, Clark NM, Polyanovsky A, Cook B, Avidor-Reiss T. A migrating ciliary gate compartmentalizes the site of axoneme assembly in Drosophila spermatids. Curr Biol. 2014;24:2622-31.

52. Styczynska-Soczka K, Jarman AP. The Drosophila homologue of Rootletin is required for mechanosensory function and ciliary rootlet formation in chordotonal sensory neurons. Cilia. 2015;4:9.

53. Baker JD, Adhikarakunnathu S, Kernan MJ. Mechanosensory-defective, male-sterile unc mutants identify a novel basal body protein required for ciliogenesis in Drosophila. Development. 2004;131:3411-22.

54. Riparbelli MG, Cabrera OA, Callaini G, Megraw TL. Unique properties of Drosophila spermatocyte primary cilia. Biol Open. 2013;2:1137-47.

55. Paridaen JT, Wilsch-Brauninger M, Huttner WB. Asymmetric inheritance of centrosome-associated primary cilium membrane directs ciliogenesis after cell division. Cell. 2013;155:333-44.

56. Khire A, Vizuet AA, Davila E, Avidor-Reiss T. Asterless reduction during spermiogenesis is regulated by Plk4 and is essential for zygote development in Drosophila. Curr Biol. 2015;25:2956-63.

57. Wilson PG, Fuller MT, Borisy GG. Monastral bipolar spindles: implications for dynamic centrosome organization. J Cell Sci. 1997;110(Pt 4):451-64.

58. Avidor-Reiss T, Khire A, Fishman EL, Jo KH. Atypical centrioles during sexual reproduction. Front Cell Dev Biol. 2015;3:21.

59. Manandhar G, Sutovsky P, Joshi HC, Stearns T, Schatten G. Centrosome reduction during mouse spermiogenesis. Dev Biol. 1998;203:424-34.

60. Wasbrough ER, Dorus S, Hester S, Howard-Murkin J, Lilley K, Wilkin E, Polpitiya A, Petritis K, Karr TL. The Drosophila melanogaster sperm proteomeII (DmSP-II). J Proteom. 2010;73:2171-85.

61. Schatten $\mathrm{G}$. The centrosome and its mode of inheritance: the reduction of the centrosome during gametogenesis and its restoration during fertilization. Dev Biol. 1994;165:299-335.
62. Walker RG, Willingham AT, Zuker CS. A Drosophila mechanosensory transduction channel. Science. 2000;287:2229-34.

63. Blachon S, Gopalakrishnan J, Omori Y, Polyanovsky A, Church A, Nicastro D, Malicki J, Avidor-Reiss T. Drosophila asterless and vertebrate Cep152 are orthologs essential for centriole duplication. Genetics. 2008;180:2081-94.

64. Bonaccorsi S, Giansanti MG, Gatti M. Spindle self-organization and cytokinesis during male meiosis in asterless mutants of Drosophila melanogaster. J Cell Biol. 1998;142:751-61.

65. Giansanti MG, Bucciarelli E, Bonaccorsi S, Gatti M. Drosophila SPD-2 is an essential centriole component required for PCM recruitment and astralmicrotubule nucleation. Curr Biol. 2008;18:303-9.

66. Goshima G, Wollman R, Goodwin SS, Zhang N, Scholey JM, Vale RD, Stuurman N. Genes required for mitotic spindle assembly in Drosophila S2 cells. Science. 2007;316:417-21.

67. Dobbelaere J, Josue F, Suijkerbuijk S, Baum B, Tapon N, Raff J. A genomewide RNAi screen to dissect centriole duplication and centrosome maturation in Drosophila. PLoS Biol. 2008;6:e224.

68. Muller H, Schmidt D, Steinbrink S, Mirgorodskaya E, Lehmann V, Habermann K, Dreher F, Gustavsson N, Kessler T, Lehrach H, et al. Proteomic and functional analysis of the mitotic Drosophila centrosome. EMBO J. 2010;29:3344-57.

69. Habermann K, Mirgorodskaya E, Gobom J, Lehmann V, Muller H, Blumlein K, Deery MJ, Czogiel I, Erdmann C, Ralser M, et al. Functional analysis of centrosomal kinase substrates in Drosophila melanogaster reveals a new function of the nuclear envelope component otefin in cell cycle progression. Mol Cell Biol. 2012;32:3554-69.

\section{Submit your next manuscript to BioMed Central and we will help you at every step:}

- We accept pre-submission inquiries

- Our selector tool helps you to find the most relevant journal

- We provide round the clock customer support

- Convenient online submission

- Thorough peer review

- Inclusion in PubMed and all major indexing services

- Maximum visibility for your research

Submit your manuscript at www.biomedcentral.com/submit
O Biomed Central 